\title{
BMJ Open Cardiac implant registries 2006-2016: a systematic review and summary of global experiences
}

\section{Shixuan Zhang, ${ }^{1,2}$ Sebastian Gaiser, ${ }^{3}$ Peter L Kolominsky-Rabas, ${ }^{1,2}$ On behalf of the National Leading-Edge Cluster Medical Technologies "Medical Valley EMN"}

To cite: Zhang S, Gaiser S, Kolominsky-Rabas PL, et al. Cardiac implant registries 2006-2016: a systematic review and summary of global experiences. BMJ Open 2018;8:e019039. doi:10.1136/ bmjopen-2017-019039

- Prepublication history and additional material for this paper are available online. To view these files, please visit the journal online (http://dx.doi. org/10.1136/bmjopen-2017019039).

Received 9 August 2017 Revised 10 January 2018 Accepted 6 March 2018
Check for updates

${ }^{1}$ Interdisciplinary Centre for Health Technology Assessment (HTA) and Public Health (IZPH), Friedrich- Alexander-University of Erlangen-Nürnberg, Erlangen, Germany

${ }^{2}$ National Leading-Edge Cluster Medical Technologies "Medical Valley EMN", Erlangen, Germany ${ }^{3}$ St Jude Medical Coordination Center BVBA, Zaventem, Belgium

Correspondence to

Shixuan Zhang;

shixuan.zhang@uk-erlangen.de

\section{ABSTRACT}

Objectives The importance of Cardiac Implant Registry (CIR) for ensuring a long-term follow-up in postmarket surveillance has been recognised and approved, but there is lack of consensus standards on how to establish a CIR. The aim of this study is to investigate the structure and key elements of CIRs in the past decade (2006-2016) and to provide recommendations on 'best practice' approaches.

Settings and participants A systematic search on CIR was employed in line with the Preferred Reporting Items for Systematic Reviews and Meta-Analyses guidelines. The following databases were searched: the PubMed (Medline), ScienceDirect and the Scopus database, EMBASE. After identifying the existing CIRs, an aggregative approach will be used to explore key elements emerging in the identified registries.

Results The following 82 registries were identified: 18 implantable cardioverterdefibrillator (ICD) registries, 7 cardiac resynchronisation therapy (CRT) registries, 5 pacemaker registries and 6 cardiovascular implantable electronic device registries which combined ICD, pacemaker and CRT implantation data; as well as 22 coronary stent registries and 24 transcatheteraortic heart valve implantation registries. While 71 national or local registries are from a single country, 44 are from European countries and 9 are located in USA. The following criteria have been summarised from the identified registries, including: registry working group, ethic issues, transparency, research objective, inclusion criteria, compulsory participation, endpoint, sample size, data collection basement, data collection methods, data entry, data validation and statistical analysis.

Conclusions Registries provide a 'real-world' picture for patients, physicians, manufacturers, payers, decisionmakers and other stakeholders. CIRs are important for regulatory decisions concerning the safety and therefore approval issues of the medical device; for payers CIRs provide evidence on the medical device benefit and drive the decision whether the product should be reimbursed or not; for hospitals CIRs' data are important for sound procurement decisions, and CIRs also help patients and their physicians to joint decision-making which of the products is the most appropriate.

\section{RATIONALE}

Any group of high-risk medical devices bears the risk of inferior products which can bring

\section{Strengths and limitations of this study}

- This study is the first review summarising global practice experience of the structure and key elements of the cardiac implant registries.

- Strength of the study is the identification of 14 key elements for designing and planning a cardiac implant registry, based on the experiences from 82 different registries.

- General limitation of a systematic review is due to the language limits, not all of the registries have been included in the review, which might cause missing data.

harms to patients and can cause additional costs to the healthcare system because the revision procedures are needed, as stated by Labek et al recently. ${ }^{1}$ These high-risk medical devices include joint implants, osteosynthesis devices, breast implants, contact lenses as well as cardiology products. ${ }^{1}$ In the field of cardiac implants, a total of 103 cases of cardiac implant adverse events have been reported in the past decade, of which 34 cases were due to battery problems. ${ }^{2}$

To solve the above-mentioned problems, technology needs to be constantly improved; setting up a complete postsurveillance system to track patients with cardiac implants is also an option. Compared with clinical studies, registries can be designed to ensure a longterm follow-up in postmarket surveillance. ${ }^{3}$ There is a clear demand from political authorities on changing from efficacy studies under ideal circumstance to effectiveness studies in a 'real-world' setting for postmarket surveillance. With the aim to raise awareness and bring evidence of the safe and good use of medical devices in the field of healthcare, WHO started to collect data of baseline country survey on medical devices from 2009, and the updated version was published in 2017. ${ }^{4}$ This baseline country survey on medical devices is designed to establish availability of 
policies, guidelines, standards and services for assessment, management and regulation of health technology in member states. But it also shows a big challenge for each country to provide complete, updated or sufficient data and records on medical devices. ${ }^{4}$ Facing these challenges, some jurisdictions started to provide frameworks for the documentation and management of medical devices. The US Food and Drug Administration (FDA) Medical Device Epidemiology Network issued 'Recommendations for a National Medical Device Evaluation System’ aiming to bridge clinical care and research through strategically coordinated registry networks in August 2015. ${ }^{5}$ Moreover, the European Commission issued in May 2017 the 'New Regulation on Medical Devices', which was heavily influenced by the preceding 'Poly Implant Prothèse' scandal in $2012 .{ }^{6} 7$

As high-risk devices, cardiac implants have specific characteristics and thus registries have to reflect their requirements. Cardiac implant registries belong to the group of product registries, which aim to investigate the performance and impact of a product in a 'real-world' setting. ${ }^{8}$ It is different from the patient registry's objective, which focuses on the severity and duration of the disease. ${ }^{8}$ Cardiac implants have different types of products. One specific category is based on using a battery inside called cardiovascular implantable electronic device (CIED) including implantable cardioverter defibrillator (ICD), pacemaker and cardiac resynchronisation therapy (CRT); the other category does not need a battery to support including coronary stents and transcatheter aortic heart valve implantation (TAVI). Although there are several cardiac implant registries worldwide, ${ }^{910}$ there is still a lack of consensus about standards on how to design a cardiac implant registry (CIR). What elements should be included to design a CIR? For different type of CIR, what should be noticed when performing each element? Questions like these to design a CIR need to be answered.

\section{Objective}

The aim of this study is to investigate the global structure and key elements of the cardiac implant registries, through an overview of existing cardiac implant registries worldwide in the past decade (2006-2016), and to provide recommendations on how to solve the problems arising from designing and planning a registry.

\section{METHODS}

\section{Search methodology}

The search was performed for articles published between 1 January 2006 and 31 December 2016 in English. The following databases were searched: the PubMed (Medline), the ScienceDirect, the Scopus database and the EMBASE via DIMID. After performing the search, citation snowballing was used to make sure that all relevant literature was found. Finally, grey literature searching has been used to search the website of CIR according to a practical tool for searching health-related grey literature published by Canada's Health Technology Assessment (HTA) Agency CADTH and recommended by University of York. ${ }^{11}$ National and international HTA web sites, clinical practice guideline producers, drug and device regulatory agencies are main grey literature source in this review. The search term regarding the name of different cardiac implants combined with registry were used as followings: ICD registry, CRT registry and pacemaker registry, coronary stent registry, TAVI registry. The search was limited to titles, abstracts in each addressed database. The full electronic search strategy for each database can be found in the online supplementary additional file 1 . The review process followed the Preferred Reporting Items for Systematic Reviews and Meta-Analyses guidelines. ${ }^{12}$

\section{Study selection}

The titles and abstracts of all retrieved articles were reviewed by two researchers (SZ and PLK-R) independently after removing the duplicated studies. If two researchers had discrepancies, the article was discussed within an internal panel of members of the leading edge cluster Medical Valley. After identifying all the relevant articles, the researchers summarised them based on the same name of the registry. From those articles published by one single registry, the most recent or most significant article regarding the registry design has been chosen. The quality of observational studies included in our review was appraised by Newcastle-Ottawa Scale (selection, comparability and outcome) criteria. ${ }^{13}$ According to the criteria described by Niederläender $e t a l,{ }^{14}$ articles are included in the review if they precisely describe the design process of a CIR. The publications were excluded if they were a single-clinical study but with the registry name. Inclusion criteria and exclusion criteria for this review were listed in table 1 .

\section{Data extraction}

To identify the key elements of registry design, the researchers aggregated findings which are relevant to the design of a CIR from each identified publication, based on 'Aggregative approaches to synthesis' described by Gough. ${ }^{15}$ The researchers took each element from identified articles which are relevant to the design of a CIR. The quality of key elements was assessed based on the criteria described by Niederläender $e t a l{ }^{14}$ This step has been

\begin{tabular}{lc}
\hline Table 1 Inclusion criteria and exclusion criteria \\
\hline Inclusion criteria & Exclusion criteria \\
\hline Cardiac implant registry. & Review, abstract, \\
- Published from January & conference notice. \\
2006 to December 2016. & Clinical studies. \\
Peer-reviewed & No complete description of \\
publications. & registry design. \\
English language. & Not for cardiac implant \\
& registry. \\
\hline
\end{tabular}




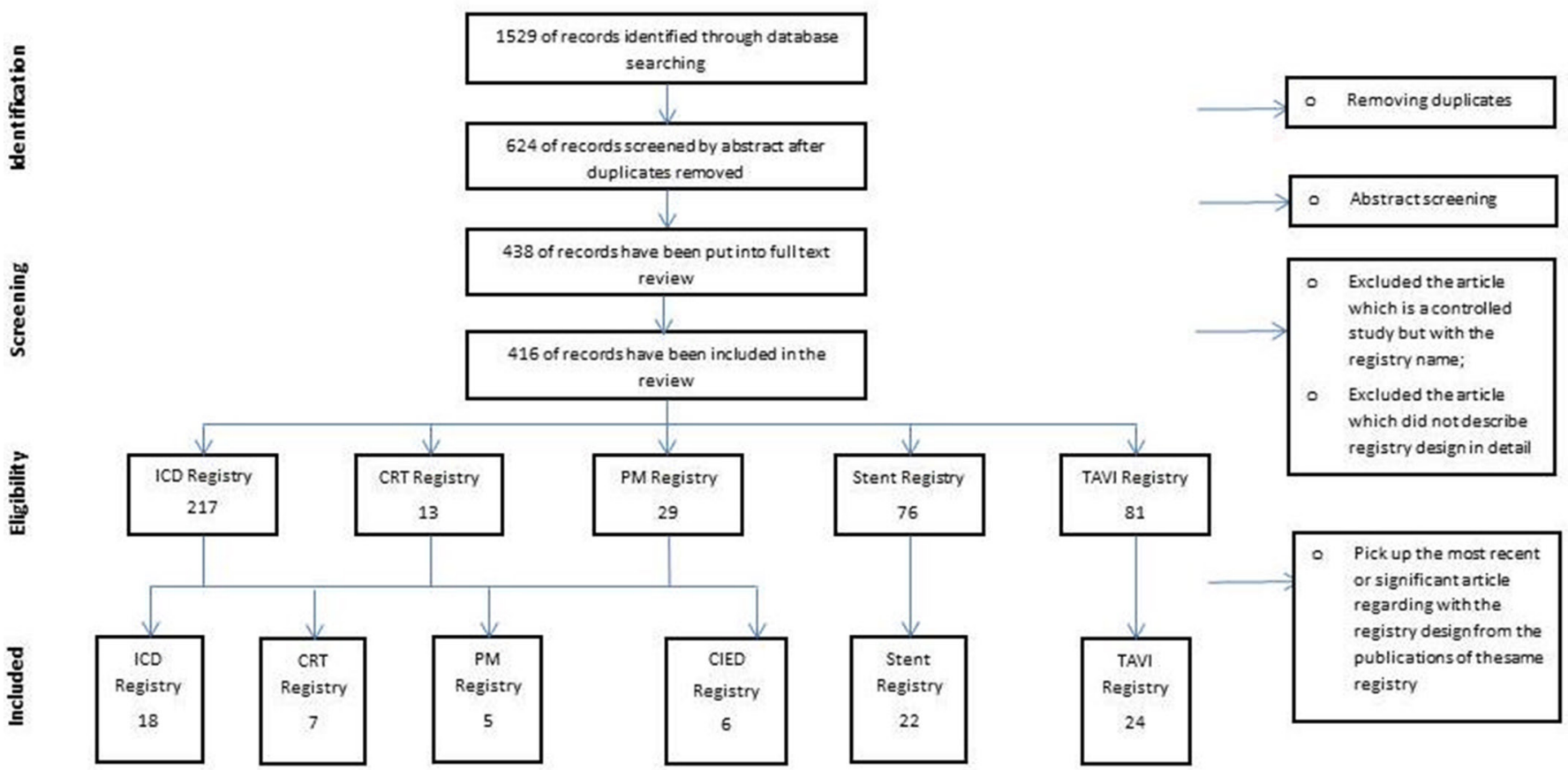

Figure 1 Preferred Reporting Items for Systematic Reviews and Meta-Analyses flow diagram of study selection. CRT, cardiac resynchronisation therapy; CIED, cardiovascular implantable electronic device; ICD, implantable cardioverter defibrillator; PM, pacemaker; TAVI, transcatheter aortic heart valve implantation.

done by two researchers (SZ and PLK-R) independently. We assessed the possibility of publication bias both visually and formally to check if the publication contains description of each element for designing a CIR.

\section{RESULTS}

\section{Bibliographic research results}

This review identified 1529 studies that were potentially relevant. Of all these studies, 406 originated from the PubMed (Medline) database, 344 from the Scopus database and 251 from the ScienceDirect, as well as 528 from the EMBASE. After removing duplicates, 624 abstracts have been reviewed by two researchers independently. Four hundred and thirty-eight articles have been put into full-text review afterwards. Four hundred and sixteen articles were actually relevant and then included in the review. Among them, 217 were related to an ICD registry, 13 were a CRT registry, 29 were about a pacemaker registry, 76 were from a coronary stent registry and 81 were from a TAVI registry. To summarise the cardiac implant registries from the identified articles, 82 registries were achieved, which is shown in figure 1. Detailed information of full electronic search strategy for each database can be found in online supplementary additional file 1 .

Figure 2 shows the distributions of global cardiac implant registries. Table 2 provides an overview of the identified cardiac registries, among all of 82 identified registries, 35 registries are ongoing registries. Specific information about the key elements of registries can be found in online supplementary additional file 2 .

\section{Key elements for designing the CIR}

A systematic 'Aggregative approaches to synthesis' described by Gough was used to collect key elements arising from identified cardiac implant registries. The results were illustrated in following text. Specific information about key elements of registry design can be found in online supplementary additional file 2 .

\section{Research objective}

Most registries were based on a clear research objective. Different kinds of research objectives can be summarised as follows: 24 registries aimed to provide a record of clinical status of the devices; 17 registries investigated safety and performance of the devices, with most of them being stent registries. Moreover, five registries examined the frequency of complications and their predictors after implantation; four registries predicted all-cause mortality of patients after implantation, most of them are CRT registries and 10 registries compared the effects of devices from different manufactures or from different procedures, most of them are TAVI registries.

\section{Participant criteria and participant requirement}

The inclusion criteria for a registry study are not as strict as those for a clinical study. Only if the registry focuses on a specified group of patients, inclusion criteria will be defined accordingly. Patient inclusion criteria are different from each type of study for an implanted device in the registries. The Stent Registry collected data usually under 'all-comers' conditions. ${ }^{16}$ Patients are classified based on different categories in the CIED registries: first 


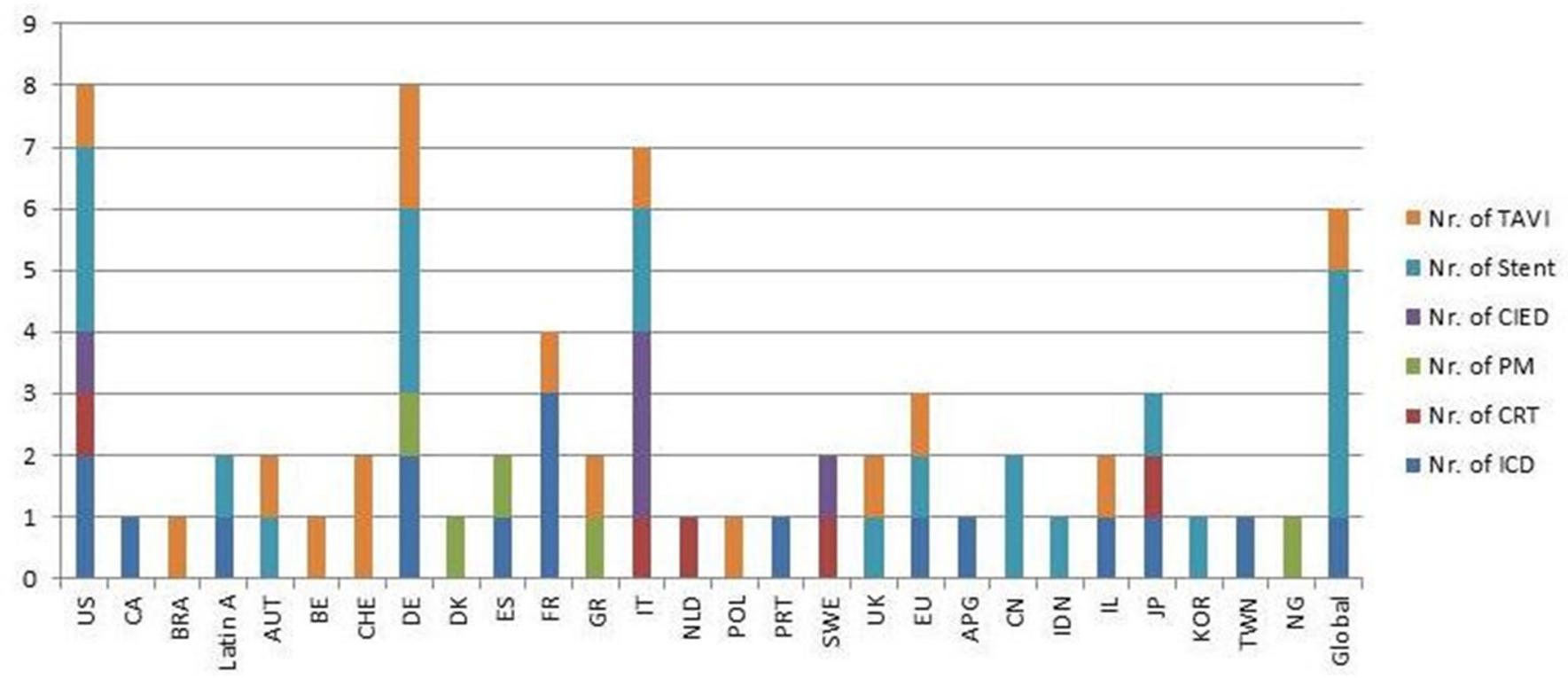

Figure 2 Location of identified cardiac implant registries. CRT, cardiac resynchronisation therapy; CIED, cardiovascular implantable electronic device; ICD, implantable cardioverter defibrillator; PM, pacemaker; TAVI, transcatheter aortic heart valve implantation.

implantation versus generation replacement and primary prevention versus secondary prevention. ${ }^{17}$ The TAVI registries usually need a dedicated heart team to determine participants' criteria. $^{18}$

Based on patients' willingness to participate, it differentiates into volunteer registry and compulsory registry. Five identified registries are compulsory registries, which have a mandatory requirement for all patients in a defined region with identified implanted device to participant. ${ }^{19-23}$ Of all 82 identified registries, four registries reported tracking patients with a unique identifier.

\section{Funding}

Funding support is crucial for registries. Out of all 82 registries, 26 are funded by public organisations, which include cardiology societies, foundations or research institutes; five are financed by their local or national governments. Seventeen are funded by manufacturers, and two registries are funded by public organisations and manufacturers cooperatively.

\section{Organisation}

All registries are cooperating with a health department. For a well-designed registry, a steering committee is necessary. The steering committees are responsible for defining the strategies, supervising the annual report and encouraging health department to participate. ${ }^{24}{ }^{25}$ Most identified registries have not provided a comprehensive description of their steering committee.

\section{Ethic approval}

Most registries have been approved by their local ethic committee or health department. The patient's consent is also required in most registries. One exception was found in the Ontario ICD Database, as a 'prescribed entity' under Ontario health information privacy legislation, the coordinating centre is allowed to collect data on all patients in this registry without informed consent. ${ }^{19}$

Research type, data collection basement and sample size

Of all 82 registries identified in our study, 69 registries collected data prospectively, 11 registries conducted a retrospective study and 2 studies conducted a prospective study also included data retrospectively. A registry can collect data from single centre or from multicentre. As shown in table 2, of all 82 identified registries, 30 are national-level multicentre registries, 5 are international-level multicentre registries and 16 are single-centre registries, the rest are regional multicentre registries.

Unlike a clinical study, a registry study usually does not set a fixed sample size in the registry design phase, they just report the sample size when they publish and analyse the data. Exceptionally, few registries have a target enrolment number like the Gulf ICD Registry. ${ }^{26}$

\section{Clinical endpoint}

Different types of registries have different clinical endpoint definitions. Major endpoints can be categorised as device-related outcomes and clinical outcomes. The TAVI registries defined an endpoint according to recommendations of the Valve Academic Research Consortium (VARC) or VARC-2, which is a standardised endpoint definition for TAVI. ${ }^{27}$ There is also clinical endpoint for coronary stent trials from Academic Research Consortium. ${ }^{29}$ However, endpoints for the CIED registry are inconsistently reported.

\section{Procedures of collecting data}

\section{Data collection}

The data have been collected either from medical records or from questionnaires. For the CIED, transmitters are able to interrogate to most of the devices, and then 
Table 2 An overview of cardiac implant registries in the last decade In multicentre, International-level multicentre; N multicentre, National-level multicentre.

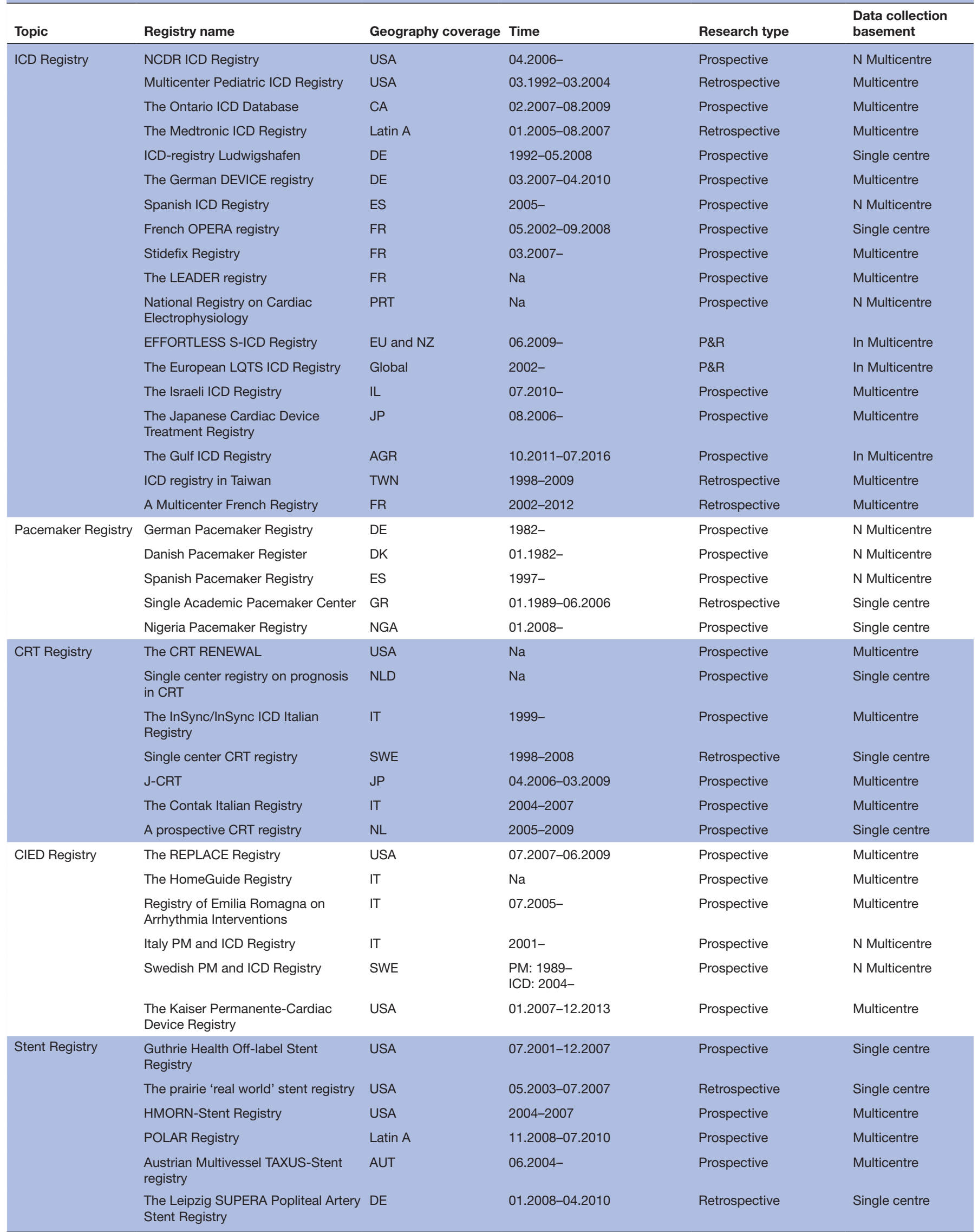

Continued 
Table 2 Continued

\begin{tabular}{|c|c|c|c|c|c|}
\hline Topic & Registry name & Geography coverage & Time & Research type & $\begin{array}{l}\text { Data collection } \\
\text { basement }\end{array}$ \\
\hline & German Cypher Stent Registry & DE & $04.2002-$ & Prospective & N Multicentre \\
\hline & German DES.DE Registry & DE & $10.2005-10-2006$ & Prospective & N Multicentre \\
\hline & WAR-STENT registry & IT & $11.2008-06.2010$ & Prospective & Multicentre \\
\hline & The Tacrolimus-Eluting STent registry & IT & $02.2005-08.2005$ & Prospective & Single centre \\
\hline & Artery Angioplasty-Stent Registry III & UK & 2005-2008 & Prospective & Multicentre \\
\hline & The Frontier stent registry & EU & $05.2002-10.2002$ & Prospective & Multicentre \\
\hline & The China CYPHER Select registry & $\mathrm{CN}$ & $07.2004-08.2005$ & Prospective & Multicentre \\
\hline & $\begin{array}{l}\text { A novel computer based stent } \\
\text { registry }\end{array}$ & IDN & $01.2002-12.2011$ & Retrospective & Single centre \\
\hline & The j-Cypher Registry & $J P$ & 08.2004-11.2006 & Prospective & Multicentre \\
\hline & The DATE registry & KOR & $12.2006-03.2008$ & Prospective & Multicentre \\
\hline & FOCUS registry & Asia & $03.2009-02.2010$ & Prospective & Multicentre \\
\hline & $\begin{array}{l}\text { The 'all comer' Coroflex Please } \\
\text { drug-eluting stent registry in Europe } \\
\text { and Asia }\end{array}$ & EU and ASIA & $09.2006-02.2008$ & Prospective & Multicentre \\
\hline & $\begin{array}{l}\text { DESERT (International Drug-Eluting } \\
\text { Stent Event Registry of Thrombosis) }\end{array}$ & Global & 04.2003- & Retrospective & Multicentre \\
\hline & The TIMI 38 Coronary Stent Registry & Global & $07.2007-07.2009$ & Prospective & Multicentre \\
\hline & E-Five Registry & Global & $10.2005-$ & Prospective & Multicentre \\
\hline & $\begin{array}{l}\text { The Korean Multicenter Drug-Eluting } \\
\text { Stent Registry }\end{array}$ & Korea & $\mathrm{Na}$ & Prospective & Multicentre \\
\hline \multirow[t]{24}{*}{ TAVI Registry } & The STS/ACC TVT Registry & USA & $05.2012-$ & Prospective & N Multicentre \\
\hline & Brazilian TAVI Registry & $\mathrm{BR}$ & $01.2008-12.2012$ & Prospective & Multicentre \\
\hline & The Austrian TAVI Registry & AUT & $01.2011-$ & Prospective & N Multicentre \\
\hline & The Belgian TAVI Registry & $\mathrm{BE}$ & $\mathrm{Na}$ & Prospective & N Multicentre \\
\hline & The Swiss TAVI registry & CHE & 2011- & Prospective & N Multicentre \\
\hline & The Bern TAVI Registry & CHE & $08.2007-04.2012$ & Prospective & Single centre \\
\hline & The Aachen TAVI registry & DE & $01.2008-$ & Prospective & Single centre \\
\hline & The German TAVI Registry & DE & 01.2009 & Prospective & N Multicentre \\
\hline & FRANCE 2 Registry & FR & 2010- & Prospective & N Multicentre \\
\hline & The ATHENS TAVR Registry & GR & $10.2009-09.2011$ & Prospective & Multicentre \\
\hline & The POL-TAVI registry & POL & 2013- & Prospective & N Multicentre \\
\hline & OBSERVANT TAVI Registry & IT & $12.2010-$ & Prospective & Multicentre \\
\hline & The UK TAVI registry & UK & 2008- & Prospective & N Multicentre \\
\hline & The Ibero-American TAVI registry & The Ibero-A & $12.2007-05.2012$ & Prospective & In Multicentre \\
\hline & $\begin{array}{l}\text { The multicentre European PARTNER } \\
\text { TAVI study }\end{array}$ & EU & $\mathrm{Na}$ & Prospective & In Multicentre \\
\hline & Rabin Medical Center TAVR registry & IL & $11.2009-08.2013$ & Prospective & Single centre \\
\hline & $\begin{array}{l}\text { The Optimized CathEter vAlvular } \\
\text { iNtervention (OCEAN-TAVI) registry }\end{array}$ & $J P$ & $10.2013-12.2014$ & Prospective & Multicentre \\
\hline & A large multicenter TAVI registry & Israel & 2008-2014 & Retrospective & Multicentre \\
\hline & The Italian CoreValve registry & IT & 2007- & Prospective & Multicentre \\
\hline & A Multicenter Spanish Registry & ES & 2014- & Prospective & Multicentre \\
\hline & A Poland single center registry & PL & 2008-2014 & Prospective & Single centre \\
\hline & $\begin{array}{l}\text { The Transcatheter Valve Treatment } \\
\text { Sentinel Pilot Registry }\end{array}$ & EU & $01.2011-05.2012$ & Prospective & Multicentre \\
\hline & The ROUTE registry & $\mathrm{PL}$ & $05.2013-06.2014$ & Prospective & Multicentre \\
\hline & $\begin{array}{l}\text { SAPIEN XT Aortic Bioprosthesis } \\
\text { Multi-Region Outcome Registry }\end{array}$ & International & $07.2010-11.2011$ & Prospective & Multicentre \\
\hline
\end{tabular}

CRT, cardiac resynchronisation therapy; DES.DE, Drug-eluting stents Deutschland; FRANCE 2, FRench Aortic National CoreValve and Edwards; HMORN-Stent, HMO Research Network-Stent; ICD, implantable cardioverter defibrillator; In multicenterre, International-level multicentreer; N multicentreer, National- level multicentre; POL-TAVI, Polish Registry of Transcatheter Aortic Valve Implantation; PM, pacemaker; STS/ACC TVT, Society of Thoracic Surgeons/American College of Cardiology Transcatheter Valve Therapy; TAVI, transcatheter aortic heart valve implantation; TAVR, Transcatheter Aortic Valve Replacement; TIMI 38, The TIMI 38 Coronary Stent. 
download data from the device, which also can support data collection and data entry. After preparing a questionnaire, there are two ways to fill out the questionnaire: either patients fill out the questionnaires by themselves with a hard copy or via an online system; or medical staffs fill out the questionnaires according to a telephone interview or a face-to-face interview.

\section{Data entry}

Most registries have a secure, web-based or a computer-based reporting system. For the single-centre registry, data entry is conducted by a trained nurse or fixed person in the working group. For the multicentre registries, participating centres entry the data into the system directly or send the data to the registry working group.

\section{Data validation}

Different methods have been found to ensure the data accuracy. The registry can check the data randomly, and assess the data by regular review, similar to an annual report. If the registry collects the data from a multicentre, each participating centre can confirm the data first, and then an independent working group in the registry can review the data again. In addition, the registry can assess if the data are complete by comparing the registry data with the manufactures' data.

\section{Public accessibility}

Of all 82 identified cardiac implant registries, six registries can be accessed via a web page, along with an annual report. The other 76 registries neither have a web-site available to the public nor an annual report. These registries can be only identified via the publications, these publications provide clinical outcomes but limited information on registry design.

\section{DISCUSSION}

To the best of our knowledge, our study is the first study to review the existing global cardiac implant registries and their practices as well as experiences. This manuscript introduces the structure and key elements, which can be seen as the first step of guidance on designing a CIR in the future and making them more appropriate for public health decision-makers as well as transparent to patients and other stakeholders. This review identified 82 cardiac implant registries from 28 countries or regions in the past decade. From these 82 registries, 9 categories with 14 key elements have been identified and illustrated in detail. The following text illustrates the recommendations and concerns arising from planning and designing a CIR.

\section{CIR's primary focus}

The primary focus of cardiac implant registries is product's safety and effectiveness. As a high-risk medical device registry, the authors summarised the following aspects needed to be noticed in the process of designing a CIR.

\section{Volunteer bias}

For a medical device registry, two kinds of volunteer bias will potentially occur: organisational-level volunteer bias and individual-level volunteer bias. ${ }^{19}$ Volunteer bias can be defined as the bias that comes from the fact that a particular sample can contain only those participants who are actually willing to participate in the study or experiment. ${ }^{30} \mathrm{In}$ our case, for a volunteer CIR, on the organisational level, centres may not participate for different reasons (low experience in the procedure, not enough staffs, not willing to publish data). On a patient level, there might be volunteer bias towards patient groups with a higher level of health awareness and/or higher socioeconomic level. To avoid volunteer bias, registries can learn from compulsory registries. Of all identified registries, five registries are compulsory registries, which were not subject to volunteer bias and were able to study all patients. For example, the Ontario Database was mandated by the administrator of healthcare services in Ontario, ${ }^{19}$ and participation from all ICD implanting centres was required. In addition, the Swiss TAVI registry has stated that consecutive patient enrolment was mandatory. ${ }^{23}$

Systematic follow-up for an adverse event reporting system

Adverse event reporting should be considered and discussed as a major focal point when planning a CIR. In addition, the registry should be capable of providing systematic follow-up event data. In our study, most of the registries summarised the event data in their publications or annual report.

\section{Rapid tracking of potentially impacted patients}

There is clear demand for the registry to take responsibility for tracking patients who have suffered from adverse events. Adverse events here indicate both device-related technique problems such as lead malfunction, and major adverse cardiovascular events (MACE) like atrial fibrillation. When an adverse event occurred, the registry should track the patients who are implanted with such devices and notify them to prevent harm. However, not all registries were capable of tracking patients. The Society of Thoracic Surgeons/American College of Cardiology Transcatheter Valve Therapy Registry added a Unique Device Identifier (UDI) field to allow tracking of specific devices, which are pending implementation of a UDI strategy by the FDA. ${ }^{31}$ This example of a patient tracking strategy and usage is close to the authors' recommendation. Political authorities began to set up a device identification system to track the patients affected. The FDA issued the complete Global Unique Device Identification Database on 26 June 2014. ${ }^{32}$ The European Commission released a recommendation for a common framework for a UDI system of medical devices in the European Union on 5 April 2013 after the first announcement in the USA. ${ }^{33}$

\section{Product generation and replacement}

Being a product which is placed in human body, cardiac implants have their own configurations nature and 
characteristics. One important area requiring attention is product generation and battery replacement. In this context, battery problems are the most frequent reasons for recalls and replacement of cardiac implants. ${ }^{2} 34$ Second, device technologies change more rapidly within a shorter time span compared with drug products. ${ }^{35}$ This rapid change demands that researchers record the product brand and specifications model within registries. Implantation devices and their providers should be described in the registry and considered when analysing data.

\section{Public accessibility}

The release of a free annual report and the accessibility on a website are the most significant strategies for disseminating registries' results. ${ }^{3}$ However, the result from our study demonstrated that there is still room for improvement. Seventy-four $(90.2 \%)$ registries can be only identified through their publications.

Data accessibility does not mean open access to the entire patient's data. Data accessibility is a way to give patients the opportunity to access information directly relevant to their condition. Since the CIR aims to prevent adverse events, accessibility and transparency is vital to both researchers and the public. Many registries are only accessible to the sponsoring organisations. To improve public health and patient care; registry findings should be available and accessible for all stakeholders. ${ }^{36}$ In an ideal setting, the communication between patients and physicians should be based on registry data. Therefore, a personalised treatment can be delivered.

Publication is a way to show the study outcome from the registry, however, the public can only find limit information about registry design. Registries in principle are a new scientific entity as stated by Labek et al ${ }^{1}$; there is a need from the research side for standardisation for creation of a CIR. If each registry describes their registry design and shares their experience with other researchers, it will improve the development of the registry study. One example of this would be sharing the requirements of randomised clinical trials (RCTs): 'all RCTs are needed to provide a protocol describing the rationale, methods, proposed analysis plan and organizational details'. ${ }^{37}$

\section{Funding source}

Funding sources and complying with the funders' purpose highlight two issues which need to be considered. Where does the funding come from? Are the funding sources capable of covering all expenditures? Stable funding source can guarantee financial support and eliminate the risk of the registry failing. Potential funding sources for registries are recommended by the 'Agency for Healthcare Research and Quality', which includes federal agencies such as government and other national governmental organisations, professional associations for instance patient groups, cardiology associations, product manufacturers such as companies or the pharmaceutical industry, as well as non-profit, private foundations and funders. ${ }^{38}$

\section{Limitation}

The main limitation of this study is that the authors are only available to search in English, so other existing and well-developed cardiac implant registries have not been included in this review. Although the authors have done a global database search, grey search and hand search, however, it is difficult to assess whether all cardiac implant registries have been identified.

\section{CONCLUSION}

The importance of cardiac implants registries has been recognised and approved, but there is lack of consensus standards on how to establish a CIR. Registries provide a 'real-world' picture for patients, physicians, manufacturers, payers, decision-makers and other stakeholders. In this context, medical device registries are important for regulatory decisions, concerning the safety and therefore approval issues of the medical device. For payers medical device registries provide evidence on the benefit of the medical device and drive the decision whether the product should be reimbursed or not. For hospitals medical device registries', data are important for sound procurement decisions, and last-and of paramount importance-medical device registries help patients and their physicians to make joint decision on which product is the most appropriate.

Contributors PLK-R provided substantial contributions to conception and design; SZ drafted the articles with acquisition of data, analysis and interpretation of data; $S G$ revised the manuscript critically for important intellectual content; PLK-R made the final approval of the version to be published. The guarantor is PLK-R.

Funding The research is supported by the German Federal Ministry of Education and Research (BMBF), project grant no: 13EX1013B, as part of the National Leading-Edge Cluster Medical Technologies 'Medical Valley EMN'. The present work was performed in (partial) fulfilment of the requirements for obtaining the degree "Dr. rer. biol. hum." at the Medical Faculty of Friedrich-Alexander University of Erlangen-Nürnberg.

Competing interests None declared.

Patient consent Not required.

Provenance and peer review Not commissioned; externally peer reviewed. Data sharing statement No additional data are available.

Open Access This is an Open Access article distributed in accordance with the Creative Commons Attribution Non Commercial (CC BY-NC 4.0) license, which permits others to distribute, remix, adapt, build upon this work non-commercially, and license their derivative works on different terms, provided the original work is properly cited and the use is non-commercial. See: http://creativecommons.org/ licenses/by-nc/4.0/

(c) Article author(s) (or their employer(s) unless otherwise stated in the text of the article) 2018. All rights reserved. No commercial use is permitted unless otherwise expressly granted.

\section{REFERENCES}

1. Labek G, Schöffl H, Stoica Cl. New regulations for medical devices: Rationale, advances and impact on research and patient care. World J Orthop 2016;7:162-6.

2. Zhang S, Kriza C, Schaller S, et al. Recalls of cardiac implants in the last decade: what lessons can we learn? PLoS One 2015;10:e0125987. 
3. Serra-Sutton V, Allepuz A, Espallargues M, et al. Arthroplasty registers: a review of international experiences. Int J Technol Assess Health Care 2009;25:63-72.

4. World Health Organization. Global atlas of medical devices. Geneva: World Health Organization, 2017.

5. Medical Device Epidemiology Network. Recommendations for a National Medical Device Evaluation System. 2015 http://www.fda.gov/downloads/aboutfda/centersoffices/ officeofmedicalproductsandtobacco/cdrh/cdrhreports/ucm 459368 . pdf

6. European Commission. Vorschlag für eine VERORDNUNG DES EUROPÄISCHEN PARLAMENTS UND DES RATES über Medizinprodukte und zur Änderung der Richtlinie 2001/83/EG, der Verordnung (EG) Nr. 178/2002 und der Verordnung (EG) Nr. 1223/2009. 2012 http://www.europarl.europa.eu/meetdocs/2009 2014/documents/com/com_com(2012)0542_/com_com(2012)0542_ de.pdf

7. European Commission. Revisions of medical device directives. Luxembourg: European Commission, 2017.

8. Bush H, Charnigo R. Collecting Health Information: Disease Registry, Product Registry, or Neither ? J Biom Biostat 2011;02:103e.

9. Niederländer C, Wahlster P, Kriza C, et al. Registries of implantable medical devices in Europe. Health Policy 2013;113:20-37.

10. Zhang S, Kolominsky-Rabas PL. How TAVI registries report clinical outcomes-A systematic review of endpoints based on VARC-2 definitions. PLoS One 2017;12:e0180815.

11. CADTH. Grey Matters: a practical tool for searching health-related grey literature. Ottawa: CADTH, 2015.

12. Liberati A, Altman DG, Tetzlaff $\mathrm{J}$, et al. The PRISMA statement for reporting systematic reviews and meta-analyses of studies that evaluate healthcare interventions: explanation and elaboration. $B M J$ 2009;339:b2700

13. Margulis AV, Pladevall M, Riera-Guardia N, et al. Quality assessment of observational studies in a drug-safety systematic review, comparison of two tools: the Newcastle-Ottawa Scale and the RTI item bank. Clin Epidemiol 2014;6:359-68.

14. Niederländer CS, Kriza C, Kolominsky-Rabas P. Quality criteria for medical device registries: best practice approaches for improving patient safety - a systematic review of international experiences. Expert Rev Med Devices 2017;14:49-64.

15. Gough D. Learning from research: systematic reviews for informing policy decisions. $2013 \mathrm{http}: / / \mathrm{www}$.alliance4usefulevidence.org/ assets/Alliance-FUE-reviews-booklet-3.pdf

16. Akin I, Nienaber CA, Richardt G, et al. Risk factors for clinical events at 1-year follow-up after drug-eluting stent implantation: results from the prospective multicenter German DES.DE registry. Clin Res Cardiol 2014;103:363-72.

17. Wasmer K, Köbe J, Andresen D, et al. Comparing outcome of patients with coronary artery disease and dilated cardiomyopathy in ICD and CRT recipients: data from the German DEVICE-registry. Clin Res Cardiol 2013;102:513-21.

18. Collas VM, Dubois C, Legrand V, et al. Midterm clinical outcome following Edwards SAPIEN or Medtronic Corevalve transcatheter aortic valve implantation (TAVI): Results of the Belgian TAVI registry. Catheter Cardiovasc Interv 2015;86:528-35.

19. Krahn AD, Lee DS, Birnie D, et al. Predictors of short-term complications after implantable cardioverter-defibrillator replacement: results from the Ontario ICD Database. Circ Arrhythm Electrophysiol 2011;4:136-42.

20. Sabbag A, Suleiman M, Glick A, et al. Ethnic differences among implantable cardioverter defibrillators recipients in Israel. Am J Cardiol 2015;115:1102-6.
21. Johansen JB, Jørgensen OD, Møller M, et al. Infection after pacemaker implantation: infection rates and risk factors associated with infection in a population-based cohort study of 46299 consecutive patients. Eur Heart J 2011;32:991-8.

22. Thylén I, Dekker RL, Jaarsma T, et al. Characteristics associated with anxiety, depressive symptoms, and quality-of-life in a large cohort of implantable cardioverter defibrillator recipients. J Psychosom Res 2014;77:122-7

23. Wenaweser P, Stortecky S, Heg D, et al. Short-term clinical outcomes among patients undergoing transcatheter aortic valve implantation in Switzerland: the Swiss TAVI registry. Eurolntervention 2014;10:982-9.

24. Rasmussen JV, Olsen BS, Fevang BT, et al. A review of national shoulder and elbow joint replacement registries. J Shoulder Elbow Surg 2012;21:1328-35.

25. Ludman PF. UK TAVI Steering Group and the National Institute for Cardiovascular Outcomes Research. The UK transcatheter aortic valve implantation registry; one of the suite of registries hosted by the National Institute for Cardiovascular Outcomes Research (NICOR). Heart 2012;98:1787-9.

26. Alsheikh-Ali AA, Hersi AS, Hamad AK, et al. The Gulf Implantable Cardioverter-defibrillator Registry: Rationale, Methodology, and Implementation. Heart Views 2015;16:125-30.

27. Kappetein AP, Head SJ, Généreux P, et al. Updated standardized endpoint definitions for transcatheter aortic valve implantation: the Valve Academic Research Consortium-2 consensus document. J Am Coll Cardiol 2012;60:1438-54.

28. Leon MB, Piazza N, Nikolsky E, et al. Standardized endpoint definitions for transcatheter aortic valve implantation clinical trials: a consensus report from the Valve Academic Research Consortium. Eur Heart J 2011;32:205-17.

29. Cutlip DE, Windecker S, Mehran R, et al. Clinical end points in coronary stent trials: a case for standardized definitions. Circulation 2007;115:2344-51.

30. Heiman GW. Research Methods in Psychology. 3rd edn. Boston \& New York: Houghton Mifflin Company, 2002.

31. Holmes DR, Nishimura RA, Grover FL, et al. Annual Outcomes With Transcatheter Valve Therapy: From the STS/ACC TVT Registry. Ann Thorac Surg 2016;101:789-800.

32. U.S. Food and Drug Administration. GUDID Guidance. 2014 http:// www.fda.gov/MedicalDevices/DeviceRegulationandGuidance/Uniqu eDeviceldentification/GlobalUDIDatabaseGUDID/ucm416106.htm

33. European Commission. COMMISSION RECOMMENDATION of 5 April 2013 on a common framework for a unique device identification system of medical devices in the Union. $2013 \mathrm{http} / / /$ eur-lex.europa.eu/LexUriServ/LexUriServ.do?uri=OJ:L:2013:099: 0017:0024:EN:PDF

34. Dean J, Sulke N. Pacemaker battery scandal. BMJ 2016;352:i228.

35. Bijwaard K, Dickey JS, Kelm K, et al. The first FDA marketing authorizations of next-generation sequencing technology and tests: challenges, solutions and impact for future assays. Expert Rev Mol Diagn 2015;15:33-40.

36. The Pew Charitable Trusts, t.B.C.B.S.A., and the Medical Device Epidemiology Network. Medical Device Registries Recommendations for Advancing Safety and Public Health. 2014 http://www.pewtrusts.org/ /media/assets/2014/09/device-registryconference-report.pdf

37. Tetzlaff JM, Chan AW, Kitchen J, et al. Guidelines for randomized clinical trial protocol content: a systematic review. Syst Rev 2012;1:1-11.

38. In: Gliklich RE DN, Leavy MB, eds. Registries for evaluating patient outcomes: a user's guide [Internet]. 3rd edn. Rockville (MD): Agency for Healthcare Research and Quality (US), 2014. 